\title{
PODA VERDE E QUALIDADE DO FRUTO DA AMEIXEIRA EM ALTA DENSIDADE
}

\author{
Ruy Inacio Neiva de Carvalho ${ }^{1}$, Giovambattista Sorrenti ${ }^{2}$, Gabriely Pinto Pereira ${ }^{1}$, Daniel William Vendramin ${ }^{1}$, \\ Raphael de Freitas Oliveira ${ }^{1}$, Ronei Emerson Kussler ${ }^{1}$
}

\begin{abstract}
${ }^{1}$ Pontifícia Universidade Católica do Paraná, Escola de Ciências Agrárias e Medicina Veterinária, Agronomia, Rua Imaculada Conceição, 1155 , Bairro Prado Velho, CEP: 80215-901Curitiba -PR, Brasil. Fone: 55413271 1534. E-mail: ruy.carvalho@pucpr.br; gabyp.pereira@hotmail.com; daniel.agro88@hotmail.com; rang_mituki@hotmail.com; rev.ronei@yahoo.com.br

${ }^{2}$ University of Bologna, Dep. of Agricultural Sciences, Viale G. Fanin 46, 40127 Bologna -Italia. Ph. +39 051 2096426, Fax +39 0512096401 .
\end{abstract} E-mail: g.sorrenti@unibo.it

Resumo - A poda verde da ameixeira é um trato cultural que mobiliza muita mão de obra, implicando em elevação do custo de produção sem garantia de aumento da qualidade da ameixa colhida. $O$ objetivo desta pesquisa foi avaliar o efeito da poda verde em ameixeiras 'Polirosa' cultivadas em alta densidade sobre a qualidade de frutos produzidos nos anos agrícolas de 2010 e 2011, em Fazenda Rio Grande, Paraná. Os tratamentos avaliados em cada ano foram: testemunha sem poda verde, uma poda verde realizada a 60 dias antes da colheita $(\mathrm{AC})$, duas podas verdes a 60 e 90 dias AC e três podas verdes realizadas a 30, 60 e 90 dias AC. Na poda verde foram eliminados os ramos ladrões com orientação vertical, ramos novos voltados ao centro da copa e o desponte dos ramos acima de $2,3 \mathrm{~m}$ do solo. Foram avaliados a massa média do fruto, os diâmetros do fruto, a acidez titulável, o grau Brix, o pH e a relação Brix/Acidez. O delineamento experimental adotado foi de blocos casualizados num esquema de parcelas subdivididas no tempo, com seis repetições. A qualidade física e química das ameixas produzidas com diversos tratamentos de poda verde não foi alterada. A diferença entre os anos de produção indicou que outros fatores estão relacionados à qualidade de ameixas 'Polirosa'. Concluiu-se que a poda verde da ameixeira 'Polirosa' em dois anos sucessivos não proporcionou incremento significativo na qualidade dos frutos colhidos.

Palavras-chave- Prunus salicina. Ameixa. Brix. Acidez.

Abstract - The green pruning of plum trees is a cultural treat that needs much labor to be performed, resulting in higher cost of fruit production without warranty of increased quality of peach harvested. The objective of this research was to evaluate the effect of green pruning plum trees 'Polirosa' in high density on the quality of fruits produced in the years 2010 and 2011 in Fazenda Rio Grande, Paraná. The treatments in each year were: control without green pruning, green pruning at 60 days before harvest (BH), two green pruning to 60 and 90 days $\mathrm{BH}$ and three green pruning at 30, 60 and 90 days $\mathrm{BH}$. The method used for pruning branches was the elimination of vertical branches facing the center of the canopy and the pruning of branches at $2.3 \mathrm{~m}$ above the ground. The variables evaluated were the fruit weight, the diameter of the fruit, acidity, Brix, pH and Brix/acidity ratio. The experimental design was a randomized block in a split plot in time, with six replications. The physical and chemical quality of plums produced with various pruning treatments was not altered. The difference between the years of production indicated that other factors are related to the quality of plums 'Polirosa'. It was concluded that the green pruning of 'Polirosa' plum tree in two successive years provided no significant increase in the quality of the fruits.

Keywords-Prunus salicina. Plum. Brix. Acidity.

Recebido em: 25 de novembro de 2015. Aprovado em: 31 de dezembro de 2015.

\section{INTRODUÇÃo}

O cultivo da ameixeira (Prunus salicina) ocorre amplamente no Sul do Brasil, mas o detalhamento de técnicas de produção ainda é necessário em função das diferentes respostas das plantas quando submetidas a manejos distintos.

A qualidade da ameixa produzida é influenciada por diversas técnicas de cultivo como o raleio (PAVANELLO; AYUB, 2012), a adubação (DOLINSKI et al., 2007) e o anelamento do tronco (ILHA et al., 1999). Além destes, a poda verde é preconizada para assegurar a qualidade e a segurança dos produtos obtidos no sistema de produção integrada e tornar a cadeia produtiva da fruta mais competitiva no mercado (TIBOLA et al., 2007). A poda da ameixeira interfere no balanço energético da planta durante todo seu desenvolvimento, do início de um novo ciclo de crescimento até a instalação de um novo período de endodormência (CARVALHO et al., 2010; PEREIRA et al., 2012).

A operação de poda em fruteiras de caroço mobiliza vários funcionários e os gastos com mão-de-obra representam de 69,3 a 75,3\% do total do custo de produção destas fruteiras no Paraná (PENTEADO JUNIOR et al., 2009). Desta forma, a operação deve ser realizada com critério, para racionalizar a condução do pomar e auxiliar na viabilização do agronegócio com esta fruteira. 
A poda verde consiste na eliminação de ramos do centro da copa e da base do tronco da planta e pode ser realizada em épocas e intensidades distintas, provocando respostas diferenciadas em função do genótipo avaliado. O método de execução da poda verde é mais estudado na cultura do pessegueiro, na qual resultados significativos foram obtidos com relação ao aumento do teor de sólidos solúveis totais e menor acidez nos frutos (TREVISAN et al., 2006). Por outro lado, a poda verde do pessegueiro pode não exercer influência sobre estes fatores (TREVISAN et al., 2008) ou até mesmo reduzir o conteúdo de sólidos solúveis nos frutos (RODRIGUES et al., 2009), uma vez que as características químicas da fruta podem sofrer influência de outros fatores externos como o clima e a adubação. Desta forma, a diferença de resposta da planta à poda verde em função de condições distintas de cultivo justifica seu estudo em uma determinada situação regional, de forma a se identificar a eficiência de sua aplicação no sistema produtivo adotado.

No estudo do efeito de tratos culturais em fruteiras perenes de clima temperado, a repetibilidade dos experimentos em anos agrícolas sucessivos é fundamental para se concluir de forma mais precisa sobre características fitotécnicas de uma cultivar (DANNER et al., 2010).

O objetivo desta pesquisa foi avaliar o efeito da poda verde em ameixeiras em alta densidade sobre a qualidade de frutos produzidos nos anos agrícolas de 2010 e 2011.

\section{MATERIAIS E MÉTODOS}

As ameixeiras (Prunus salicina cv. Polirosa) utilizadas para a pesquisa são enxertadas sobre o porta-enxerto 'Okinawa' e foram implantadas em 2003 no espaçamento de $5 \mathrm{~m}$ entre fileiras e $1,5 \mathrm{~m}$ entre plantas na Fazenda Experimental Gralha Azul da PUCPR, no município de Fazenda Rio Grande, Paraná. Foram estudadas as safras de 2010 e 2011 , quando as plantas estavam no $7^{\circ}$ e $8^{\circ}$ ano do pomar.

O pomar está sendo conduzido no sistema adensado em ' $\mathrm{Y}$ ' com plantas recebendo a poda de contenção da altura a 2,3 m do solo no início do outono. As podas verdes estudadas foram realizadas no período do florescimento até a colheita dos frutos, que se estende de agosto a dezembro na região. Já ao final do florescimento, ramos mal localizados podiam ser visualizados e eliminados, conforme os tratamentos adotados. O raleio de frutinhos foi realizado na segunda quinzena de setembro. Os tratamentos fitossanitários realizados foram aqueles adotados na rotina do pomar e recomendados para a cultura (MEDEIROS; RASEIRA, 1998).

Os tratamentos aplicados nas plantas em cada ano foram: testemunha sem poda verde, uma poda verde realizada a 60 dias antes da colheita, duas podas verdes a 90 e 60 dias antes da colheita e três podas verdes realizadas a 90, 60 e 30 dias antes da colheita. Na poda verde foram eliminados os ramos ladrões com orientação vertical, ramos novos voltados ao centro da copa e o desponte dos ramos acima de 2,3 $\mathrm{m}$ do solo. Os ramos podados foram levados a estufa de secagem a $62{ }^{\circ} \mathrm{C}$ por $42 \mathrm{~h}$ para determinação da massa seca em balança com precisão de $0,01 \mathrm{~g}$.

De cada planta estudada foi retirada uma amostra aleatória e representativa de cinco frutos no ponto de colheita que foi levada para o laboratório para execução das análises físicas de massa fresca de fruto $(\mathrm{g})$ em balança de precisão de $0,01 \mathrm{~g}$ e diâmetros meridional e equatorial $(\mathrm{mm})$ com paquímetro manual com precisão de $0,1 \mathrm{~mm}$. Para a análise do $\mathrm{pH}$, foram separados em um becker $10 \mathrm{~mL}$ de suco dos frutos da amostra e adicionados $90 \mathrm{~mL}$ de água deionizada. A mistura foi agitada para posterior leitura em pHmetro. As análises de sólidos solúveis totais foram realizadas com gotas do suco para observação em refratômetro portátil com precisão de $0,1^{\circ}$ Brix. Foram realizadas análises em duplicata em cada fruto. A acidez foi determinada por meio da titulação da solução de $10 \mathrm{~mL}$ do suco mais $90 \mathrm{~mL}$ de água deionizada com $\mathrm{NaOH} 0,1 \mathrm{~N}$ até atingir o $\mathrm{pH} 8,1$.

O delineamento experimental adotado foi de blocos casualizados num esquema de parcelas subdivididas no tempo, formado pelos quatro tratamentos de poda verde na parcela principal e os dois anos agrícolas na subparcela, com seis repetições. Cada parcela foi constituída por três plantas, sendo a planta central a avaliada, totalizando 72 plantas. Os dados foram submetidos à análise de variância e as médias com diferença pelo Teste $\mathrm{F}$ foram submetidas ao Teste Tukey $(\mathrm{p} \leq 0,05)$.

\section{RESULTADOS E DISCUSSÃO}

A realização da poda verde em épocas distintas resultou em diferentes massas secas de ramos retirados das plantas, fato que se repetiu nos dois anos avaliados. Quando a poda foi iniciada aos 90 dias antes da colheita (AC) e repetida aos 60 dias $\mathrm{AC}$, foi retirada a menor massa de ramos. Quando a poda foi feita somente aos 60 dias AC, a massa podada foi maior indicando que a antecipação do início da poda verde reduz o vigor dos ramos a serem podados aos 60 dias AC (Tabela 1). Estes ramos retirados na operação da poda representam drenos de fotoassimilados que concorrem com os frutos na planta. Porém, após os 60 dias $\mathrm{AC}$ o crescimento de ramos indesejáveis continua a ocorrer com vigor, visto que na poda realizada aos 30 dias $\mathrm{AC}$, muitos ramos ainda foram eliminados da planta. Este comportamento ocorreu nos dois anos estudados, com valores mais elevados no segundo ano, em que foram retirados $941,4 \mathrm{~g}$ de massa seca de ramos em três podas verdes.

As características físicas do fruto não foram alteradas em função da poda verde realizada, porém uma variação foi detectada quando comparados os dois anos estudados (Tabela 2). Este resultado salienta o fato de que as avaliações repetidas em ciclos sucessivos são fundamentais para se certificar a respeito do efeito de um trato cultural sobre características fitotécnicas de uma cultivar de fruteira perene (DANNER et al., 2010). A massa média do fruto colhido foi de $61,1 \mathrm{~g}$ em $2010 \mathrm{e}$ 67,1 em 2011. Estes valores são elevados quando comparados aos obtidos para outras cultivares de ameixa como de $40 \mathrm{~g}$ para a 'Irati' (PAVANELLO; AYUB, 
2012) e entre 56 e 62 g para a 'Amarelinha' (ILHA et al., 1999). Dolinski et al. (2007) encontraram massa média de frutos da ameixa 'Reubennel' entre 53 e $65 \mathrm{~g}$.

Tabela 1 - Massa seca de ramos retirados com a poda verde de ameixeira 'Polirosa' em diferentes épocas nas safras de 2010 e 2011 em Fazenda Rio Grande, Paraná.

\begin{tabular}{lcc}
\hline \multicolumn{1}{c}{ Época de poda verde } & \multicolumn{2}{c}{$\begin{array}{c}\text { Massa seca de ramos } \\
\text { podados }\left(\mathrm{g} \text { planta }^{-1}\right)\end{array}$} \\
\cline { 2 - 3 } (dias antes da colheita) & 2010 & 2011 \\
\hline Sem poda & 0 & 0 \\
60 dias & 393,8 & 549,1 \\
60 e 90 dias & 286,8 & 276,1 \\
30,60 e 90 dias & 475,1 & 941,4 \\
\hline
\end{tabular}

No ano de 2010 foram colhidos frutos de maior diâmetro meridional em relação a 2011, o que significa um fruto mais alongado (Tabela 3). A maior massa seca de ramos retirada das plantas em 2011 pode estar relacionada com a produção de frutos de menor diâmetro meridional neste ano. Por outro lado, em um mesmo ciclo, a permanência dos ramos na planta testemunha sem poda não prejudicou a qualidade do fruto em relação àqueles das plantas que receberam a poda verde. As alterações ocorridas no diâmetro meridional e equatorial do fruto entre os anos estudados identificam a variação da forma do fruto de uma safra para outra, embora a massa tenha sido pouco alterada.

Tabela 2 - Massa de ameixas 'Polirosa' após diferentes épocas de poda verde nas safras de 2010 e 2011 em Fazenda Rio Grande, Paraná.

\begin{tabular}{|c|c|c|}
\hline \multirow{2}{*}{$\begin{array}{c}\text { Época de } \\
\text { poda verde } \\
\text { (dias antes } \\
\text { da colheita) }\end{array}$} & \multicolumn{2}{|c|}{$\begin{array}{c}\text { Massa do fruto } \\
\left(\text { g.fruto }^{-1}\right)^{*}\end{array}$} \\
\hline & 2010 & 2011 \\
\hline Sem poda & $63,6 \mathrm{Aa}$ & $70,8 \mathrm{Aa}$ \\
\hline 60 & $59,0 \mathrm{Ab}$ & $69,9 \mathrm{Aa}$ \\
\hline 60 e 90 & $61,0 \mathrm{Aa}$ & $58,9 \mathrm{Aa}$ \\
\hline 30,60 e 90 & $60,6 \mathrm{Aa}$ & $68,6 \mathrm{Aa}$ \\
\hline CVpoda (\%) & \multicolumn{2}{|c|}{13,6} \\
\hline CVano (\%) & \multicolumn{2}{|c|}{11,4} \\
\hline
\end{tabular}

*Médias seguidas por letras distintas maiúsculas nas colunas e minúsculas nas linhas diferem entre si pelo teste Tukey ( $\mathrm{p} \leq$ $0,05)$.

As características químicas de $\mathrm{pH}$, acidez e a relação Brix/acidez dos frutos não foram alteradas pela execução da poda verde nas plantas em uma mesma safra, porém a acidez e a relação Brix/acidez sofreram alterações em função do ano avaliado (Tabelas 4 e 5). Embora a execução da poda verde proporcione a alteração da relação fonte-dreno da planta, esta interferência nem sempre resulta em alterações significativas, como para algumas cultivares de pessegueiro (TREVISAN et al., 2008). Apenas a acidez do suco da fruta foi menor na safra de 2011 quando realizada a poda aos 60 e 90 dias AC e, consequentemente, neste ano a relação Brix/acidez foi maior.
Tabela 3 - Tamanho de ameixas 'Polirosa' após diferentes épocas de poda verde nas safras de 2010 e 2011 em Fazenda Rio Grande, Paraná.

\begin{tabular}{|c|c|c|c|c|}
\hline \multirow{2}{*}{$\begin{array}{l}\text { Época de } \\
\text { poda verde } \\
\text { (dias antes } \\
\text { da colheita) }\end{array}$} & \multicolumn{2}{|c|}{$\begin{array}{c}\text { Diâmetro } \\
\text { meridional } \\
(\mathrm{mm})^{*}\end{array}$} & \multicolumn{2}{|c|}{$\begin{array}{c}\text { Diâmetro } \\
\text { equatorial } \\
(\mathrm{mm})^{*}\end{array}$} \\
\hline & 2010 & 2011 & 2010 & 2011 \\
\hline Sem poda & $49,9 \mathrm{Aa}$ & $44,6 \mathrm{Ab}$ & $45,9 \mathrm{Aa}$ & $48,4 \mathrm{Aa}$ \\
\hline 60 & $48,3 \mathrm{Aa}$ & $45,0 \mathrm{Ab}$ & $45,8 \mathrm{Ab}$ & 49,1 Aa \\
\hline 60 e 90 & $49,1 \mathrm{Aa}$ & $43,4 \mathrm{Ab}$ & $45,8 \mathrm{Aa}$ & 47,9 Aa \\
\hline su, ou e yu & 48,0 Aa & $4 \supset, \supset \mathrm{AD}$ & $4 \supset, \mathrm{CAD}$ & 48,5 Aa \\
\hline CVpoda $(\%)$ & \multicolumn{2}{|c|}{5,0} & \multicolumn{2}{|c|}{4,2} \\
\hline CVano (\%) & \multicolumn{2}{|c|}{4,8} & \multicolumn{2}{|c|}{4,5} \\
\hline
\end{tabular}

*Médias seguidas por letras distintas maiúsculas nas colunas e minúsculas nas linhas diferem entre si pelo teste Tukey ( $\mathrm{p} \leq$ $0,05)$.

Tabela 4 - Acidez e pH de ameixas 'Poli Rosa' após diferentes épocas de poda verde nas safras de 2010 e 2011 em Fazenda Rio Grande, Paraná.

\begin{tabular}{|c|c|c|c|c|}
\hline \multirow{2}{*}{$\begin{array}{c}\text { Época de poda } \\
\text { verde } \\
\text { (dias antes } \\
\text { da colheita) } \\
\end{array}$} & \multicolumn{2}{|c|}{$\mathrm{pH}^{* *}$} & \multicolumn{2}{|c|}{ Acidez* } \\
\hline & 2010 & 2011 & 2010 & 2011 \\
\hline Sem poda & 4,2 & 4,6 & $4,8 \mathrm{Aa}$ & $3,6 \mathrm{Aa}$ \\
\hline 60 dias & 4,3 & 4,6 & 4,8 Aa & 3,7 Aa \\
\hline 60 e 90 dias & 3,9 & 4,5 & $5,2 \mathrm{Aa}$ & $2,9 \mathrm{Ab}$ \\
\hline 30,60 e 90 dias & 3,9 & 4,4 & $4,5 \mathrm{Aa}$ & $4,3 \mathrm{Aa}$ \\
\hline CVpoda (\%) & \multicolumn{2}{|c|}{9,8} & \multicolumn{2}{|c|}{30,1} \\
\hline CVano (\%) & \multicolumn{2}{|c|}{12,8} & \multicolumn{2}{|c|}{44,0} \\
\hline
\end{tabular}

*Médias seguidas por letras distintas maiúsculas nas colunas e minúsculas nas linhas diferem entre si pelo teste Tukey $(\mathrm{p} \leq 0,05)$.

**Diferenças não significativas.

Tabela 5 - Relação Brix/acidez and ${ }^{\circ}$ Brix de ameixas 'Polirosa' após diferentes épocas de poda verde nas safras de 2010 e 2011 em Fazenda Rio Grande, Paraná.

\begin{tabular}{lccccc}
\hline $\begin{array}{c}\text { Época de } \\
\text { poda verde } \\
\text { (dias antes }\end{array}$ & \multicolumn{2}{c}{${ }^{\circ}$ Brix* } & \multicolumn{3}{c}{$\begin{array}{c}\text { Relação } \\
\text { Brix/Acidez* }\end{array}$} \\
\cline { 2 - 3 } da colheita) & 2010 & 2011 & & 2010 & 2011 \\
\hline Sem poda & $9,8 \mathrm{Aa}$ & $8,3 \mathrm{Ab}$ & & $2,2 \mathrm{Aa}$ & $2,5 \mathrm{Aa}$ \\
60 & $9,2 \mathrm{ABa}$ & $8,0 \mathrm{Aa}$ & & $2,2 \mathrm{Aa}$ & $2,2 \mathrm{Aa}$ \\
60 e 90 & $7,8 \mathrm{Ba}$ & $8,6 \mathrm{Aa}$ & & $1,6 \mathrm{Ab}$ & $3,4 \mathrm{Aa}$ \\
$30,60 \mathrm{e} 90$ & $8,3 \mathrm{Ba}$ & $7,2 \mathrm{Aa}$ & & $2,0 \mathrm{Aa}$ & $2,3 \mathrm{Aa}$ \\
\hline CVpoda $(\%)$ & \multicolumn{2}{c}{11,6} & \multicolumn{2}{c}{31,9} \\
\hline CVano $(\%)$ & \multicolumn{2}{c}{12,3} & \multicolumn{2}{c}{45,8} \\
\hline
\end{tabular}

* Médias seguidas por letras distintas maiúsculas nas colunas e minúsculas nas linhas diferem entre si pelo teste Tukey ( $\mathrm{p} \leq$ $0,05)$.

Os valores de $\mathrm{pH}$ foram homogêneos e ficaram entre 3,9 e 4,6 nos dois anos avaliados. Estes valores podem ser considerados elevados quando comparados a outras cultivares de ameixa como a 'Irati' com pH 3,0 (PAVANELLO; AYUB, 2012), a 'Golf Blaze' com pH de 3,1 a 3,9 (CHAGAS, 2008), a 'Reubennel' com pH 3,02 (BRACKMANN et al., 2005; CHAGAS, 2008) e a 'Amarelinha' com pH em torno de 3,5 (ILHA et al., 
1999). Frutos com maior $\mathrm{pH}$ estão associados com menor acidez, o que reflete diretamente no seu sabor.

O teor de sólidos solúveis no suco $\left({ }^{\circ}\right.$ Brix $)$ apresentou variação em função da poda realizada no ano de 2010, quando foram produzidos os frutos de maior diâmetro meridional. Porém, os frutos de ${ }^{\circ}$ Brix mais elevado foram colhidos nas plantas testemunhas e naquelas que receberam apenas uma poda verde aos 60 dias antes da colheita, ou seja, que mantiveram na copa maior massa de ramos (Tabela 5).

Verificou-se que a frequência da poda verde de duas a três vezes em 2010, durante o crescimento do fruto, implicou em colheita de frutos com menor teor de sólidos solúveis em relação às plantas sem poda, de forma que os ramos remanescentes na planta foram também responsáveis pelo equilíbrio da copa e geração de fotoassimilados para os frutos. Porém, na safra seguinte, quando as plantas apresentaram crescimento vegetativo mais vigoroso, este fato não ocorreu (Tabela $5)$.

O teor de sólidos solúveis dos frutos $\left({ }^{\circ}\right.$ Brix $)$ variou entre 7,2 e 9,2 nos dois anos estudados. Estes valores podem ser considerados baixos quando comparados aos encontrados para outras cultivares de ameixa como a 'Irati' com média de 9,5 ${ }^{\circ}$ Brix (PAVANELLO; AYUB, 2012), a 'Golf Blaze' com média 12 a $13{ }^{\circ}$ Brix (CHAGAS, 2008), a 'Reubennel' com média de 12 a 15,3 ${ }^{\circ}$ Brix (BRACKMANN et al., 2005; CHAGAS, 2008) e a 'Amarelinha' com média entre 13 e $14^{\circ}$ Brix (ILHA et al., 1999).

A poda verde da ameixeira 'Polirosa' em dois anos sucessivos não proporcionou incremento significativo na qualidade dos frutos colhidos. Como a operação de poda em fruteiras de caroço mobiliza vários funcionários e os gastos com mão-de-obra representam de 69,3 a $75,3 \%$ do total do custo de produção no Estado do Paraná (PENTEADO JUNIOR et al., 2009), a operação realizada nas condições do pomar deve ser realizada com critério, pois o investimento de mão-de-obra não proporcionou retorno de qualidade física e química do fruto produzido. A diferença entre os anos de produção, independentemente da operação da poda, indicou que outros fatores fitotécnicos e ambientais estão relacionados à qualidade de ameixas 'Polirosa'.

\section{CONCLUSÃO}

Nas condições em que o estudo foi realizado, foi possível concluir que a poda verde da ameixeira 'Polirosa' não proporcionou incremento significativo na qualidade dos frutos colhidos.

\section{REFERÊNCIAS}

BRACKMANN, A.; BENEDETTI, M.; HUNSCHE, M.; SESTARI, I. Armazenamento de ameixas cvs. Reubennel e Pluma 7 sob diferentes temperaturas, em atmosfera controlada e refrigerada. Revista Brasileira de Agrociência, Pelotas, v.11, p.85-89, 2005.
CARVALHO, R.I.N.; BIASI, L.A.; ZANETTE, F.; RENDOKE, J.C.; SANTOS, J.M.; PEREIRA, G.P. Endodormência de gemas de pessegueiro e ameixeira em região de baixa ocorrência de frio. Revista Brasileira de Fruticultura, Jaoticabal, v.32, p.769-777, 2010.

CHAGAS, P.C. Cultivares de ameixa de baixa exigência em frio para regiões subtropicais do Estado de São Paulo. 2008. Dissertação (Mestrado em Fitotecnia) - Escola Superior de Agricultura Luiz de Queiroz, Universidade de São Paulo, Piracicaba, 2008.

DANNER, M.A. et al. Repetibilidade de peso de fruto e de duração do ciclo em ameixeira e pessegueiro. Pesquisa Agropecuária Brasileira, Brasília, v.45, p.872$878,2010$.

DOLINSKI, M.A. et al. Adubação nitrogenada e potássica na produtividade da ameixeira 'Reubennel', na região de Araucária - PR. Revista Brasileira de Fruticultura, Jaboticabal, v.2, p.364-370, 2007.

ILHA, L.L.H. et al. Efeito do raleio e do anelamento do tronco no crescimento, produção e qualidade da ameixeira japonesa. Pesquisa Agropecuária Brasileira, Brasília, v.34, p.2211-2217, 1999.

MEDEIROS, C.A.B.; RASEIRA, M.C.B. A cultura do pessegueiro. Brasília: Embrapa-SPI; Pelotas: EmbrapaCPACT, 1998.

PAVANELLO, A.P.; AYUB, R.A. Aplicação de ethephon no raleio químico de ameixeira e seu efeito sobre a produtividade. Revista Brasileira de Fruticultura, Jaboticabal, v.34, p.309-316, 2012.

PENTEADO JUNIOR, J.F.; MAY DE MIO, L.L.; RODIGHERI, H.R. Avaliação dos custos em pomares de pessegueiro conduzidos nos sistemas integrado e convencional, nos municípios de Araucária e Lapa, Paraná. Ciência Rural, Santa Maria, v.39, p.2521-2526, 2009.

PEREIRA, G.P.; CARVALHO, R.I.N.; BIASI, L.A.; ZANETTE, F. Dinâmica da dormência de gemas de pessegueiro, ameixeira e caquizeiro na Fazenda Rio Grande, PR. Revista Brasileira de Ciências Agrárias, Pernambuco, v.7, p.820-825, 2012.

RODRIGUES, A. et al. Desenvolvimento do pessegueiro 'Flordaprince' sob duas intensidades de poda verde. Bragantia, Campinas, v.68, p.673-679, 2009.

TIBOLA, C.S. et al. Análise da conformidade na adoção das normas de produção integrada de pêssego. Ciência Rural, Santa Maria, v.37, p.1149-1152, 2007. 
TREVISAN, R.; HERTER, F.G.; COUTINHO, E.F.; GONÇALVES, E.D.; SILVEIRA, C.A.P.; FREIRE, TREVISAN, Renato et al.. Uso de poda verde, plásticos refletivos, antitranspirante e potássio na produção de pêssegos. Pesquisa Agropecuária Brasileira, Brasília, v.41, p.1485-1490, 2006.
TREVISAN, R. et al. Influência do plástico branco, poda verde e amino quelant ${ }^{\circledR}-\mathrm{K}$ na qualidade de pêssegos 'Santa Áurea'. Bragantia, Campinas, v.67, p.243247, 2008. 